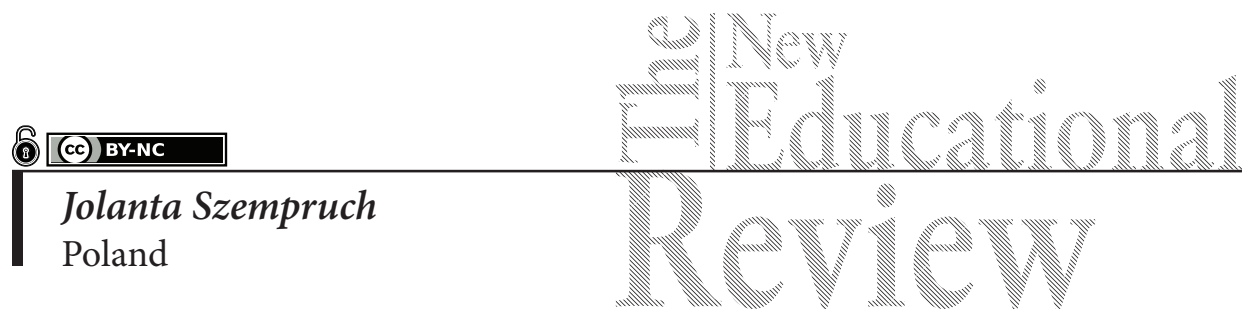

\title{
Feeling of Professional Burnout in Teachers of Secondary Schools
}

DOI: 10.15804/tner.2018.54.4.18

\begin{abstract}
The paper presents the results of research on the feelings of professional burnout in teachers of secondary schools. In its first part, a professional burnout model is presented, as well as symptoms and consequences of the burnout process. Then, main sources of burnout, common prevention strategies, and main areas where signs of burnout can occur are discussed. An important part of the paper is formed by the analysis of the results of a survey conducted among 315 teachers in the Lublin and Starachowice districts. It is worrying that, according to the research, every fifth teacher is characterised by very high or high level of the professional burnout feeling. Therefore, the necessity to prepare future teachers - already at the stage of their education - to cope with unusual educational situations and apply strategies preventing professional burnout, turns out to be of particular significance. These issues are reflected on in the conclusions and recommendations for teachers, included in this paper.
\end{abstract}

Keywords: professional burnout, stress, teacher, depersonalisation, emotional exhaustion, prevention activities, low personal accomplishment

\section{Introduction}

The professional burnout syndrome is a multi-faceted phenomenon. It is characterised by complex causes, symptoms, and consequences. As a vocational issue, it calls for a number of prevention measures to be taken, focused on structural and 
organisational changes in school. As an individual problem of the teacher, it can be overcome mainly through an effective defence system and an individual strategy developed by the person concerned.

The notion of research on the phenomenon of professional burnout is associated with civilisation changes and growing expectations placed on the professions which, in their essence, are human services. Professional burnout was described for the first time as late as in the 1970s. It occurs in representatives of professions that require close interactions with other people and involvement in their fate. The costs of such interactions, permanent confrontation with negative emotions and chronic stress are so intense that the person is not able to manage their professional burden. In such a situation, defensive reactions are triggered, such as distancing oneself from people and situations, perceiving clients in a dehumanised manner, which is a sign of depersonalisation - a phenomenon characteristic of professional burnout. As the work-related psychical and physical strain persists, professional satisfaction decreases and professional commitment is lost.

\section{Theoretical Background}

\section{Professional burnout model}

There are many definitions of professional burnout. The most popular one was provided by Ch. Maslach and S. Jackson (1986), who developed a ternary professional burnout model (diagram 1).

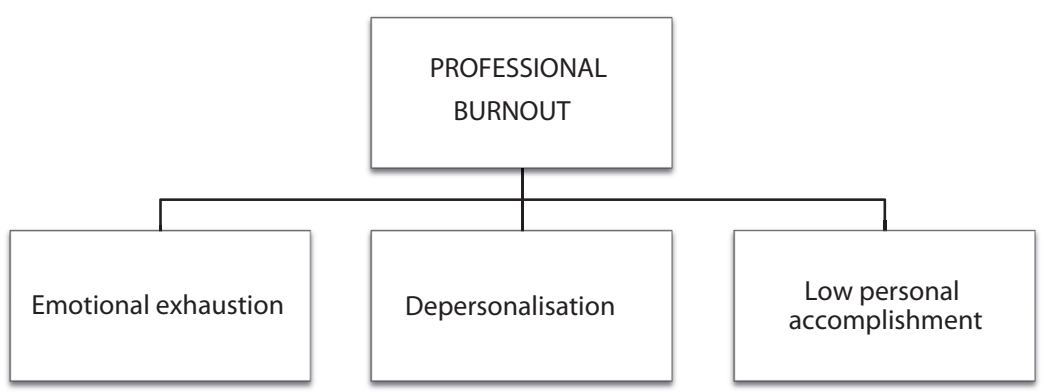

Source: own study on the basis of: C. Maslach, S. Jackson (1986) Maslach Burnout Inventory. Manual (ed. 2.), Palo Alto, CA, Consulting Psychologists Press.

Diagram 1. A three-stage professional burnout model 
The authors define professional burnout as a psychological syndrome of emotional exhaustion, depersonalisation, and reduced personal accomplishment, which can occur among individuals who work with other people in some capacity. Emotional exhaustion refers to the individual's subjective feeling that they are emotionally overburdened. This results from the fact that such an individual intensely experiences problems of other people, while at the same time feeling responsible for their fate and blaming her/himself when she/he is not able to provide effective help at the right time. At this stage of professional burnout, the individual feels energy loss, headache, joylessness, weariness, insomnia, hypersensitivity, proneness to sudden reactions and impulsiveness. The symptoms observed also include a state of internal tension and generalised anxiety. Emotional exhaustion points to the fact that the person performs a given job above their limits, while at the same time not receiving support from others. Depersonalisation, in turn, is characterised by avoiding physical and psychical contact with the subjects of professional interaction, a negative, heartless or overly indifferent reaction to clients, their parents, and colleagues, a lack of interest in problems and demonstrating their aversion. The teacher is characterised by lack of empathy and even dehumanisation associated with the loss of idealism, by negative attitude and cynicism. This group of symptoms is the most "costly" consequence of the burnout process. The last stage of professional burnout is related to reduced personal accomplishment and professional satisfaction, leading to feelings of futility and resignation. It connects all the above-described symptoms. The teacher shows tendency to assess themselves negatively, particularly with regard to their work, to feelings of decreased competence and work efficiency, while abrasiveness and a sense of grievance are on the rise. This leads to perceiving him/herself as an incompetent and ineffective person, unable to correctly perform his/her professional tasks a person who is depressed, tired and sluggish.

According to Ch. Maslach (1982), emotional exhaustion occurs first in the burnout syndrome, and results from the stress experienced by the individual. Then comes depersonalisation, resulting from failure in coping with emotional exhaustion, and finally - reduced personal accomplishment.

There were numerous attempts to describe and classify stages of professional burnout based on the three constitutive elements indicated by Ch. Maslach (cf., M. Burisch, 1989, p. 12). The burnout dynamics was also described in the concept of J. Edelwich and A. Brodsky, who presented it as a process of growing disillusionment. They discerned four stages: enthusiasm, stagnation, frustration, and apathy. Since such a situation points out to the need for response measures in the form of professional help, they also identified the fifth stage of burnout, namely intervention (J. Edelwich, A. Brodsky, 1980). 
Analysis of burnout shows that it is not easy to conceptualise this phenomenon, as it includes multiple dimensions, including individual, interpersonal, and institutional ones. Therefore, different accounts of this phenomenon should be treated as complementary, since only such a perspective will allow for understanding the complex structure of professional burnout.

Given the multitude and diversity of the symptoms of the professional burnout syndrome, one should bear in mind that if one or a couple of them occur in a person, it does not necessarily mean a threat of burnout. However, the subjective feeling of a degree of intenseness of a given symptom can also indicate the burnout stage at which the individual finds themselves, which makes it easier to undertake steps preventing further development of the syndrome. It is crucial here to perform self-diagnosis to exclude other entities such as stress, depression, or a chronic fatigue syndrome.

\section{Sources of professional burnout}

It is important to remember that the burnout syndrome affects persons who are initially characterised by idealism, motivation, passion and commitment in their professional life. While a person without such features may experience tiredness, depression, stress, or existential crisis, they are not affected by burnout. According to I. Friedman (2000, p. 601), burnout may result in adaptation, recovery, and continuation of professional work, or abandonment of the profession.

The causes of professional burnout should be sought both in the subjective and extra-subjective area. Professional burnout as a result of the process of gradual disillusionment is an aftermath of failing in achieving the expected and desired objective, and the long-term involvement in emotionally burdening situations. People committed to their work and emotionally involved in it, who expect to derive a sense of life from it, are exposed to professional burnout when they fail. The major source of burnout is teachers' inability to create the sense of mastery and self-efficacy (C. Cherniss, 1993, pp. 130-150). An important cause of burnout is also emotional overburdening and the consequent emotional exhaustion, in particular when the emotional requirements are overwhelming and one is unable to react to them in a satisfactory way (A.M. Pines, E. Aronson, 1988, p. 9). In such circumstances, they lead to a subjective feeling of failure which, for a person expecting to find a sense of life in work, is shattering.

One of the important sources of professional burnout is stress. It is a natural biological reaction of the system to day-to-day challenges and major changes - not 
only negative, but also positive. Lazarus discerns: (1) systemic stress, connected with disorders in tissue systems; (2) psychological stress, associated with cognitive factors leading to the assessment of threat, an (3) social stress, related to disturbance of a social individual or a social system (A. Monat, R. Lazarus, 1985).

Every teacher can experience stress, as it is inherent to the profession. However, not all stress conditions the development of professional burnout. The latter may be experienced by a teacher who was strongly motivated, professionally committed and had high expectations when starting to work. A person who from the beginning lacks a high level of motivation may experience work-related stress, but not burnout. The basis for the development of burnout is cumulation of negative experiences of failure in coping with stress, and development of a belief that one is unable to effectively cope with difficulties.

\section{Prevention of professional burnout}

Optimal protection of teachers against burnout should include primary, secondary, and tertiary prevention. The primary level of burnout prevention consists in removal of its possible sources, the second one - in modification of the individual's reactions to stressors, and the third level involves reducing the degree of negative influence of burnout consequences. Teachers should be able to timely undertake relevant prevention activities. Examples of preventing the cumulation of negative stress consequences were presented, inter alia, by Garry Hornby, Eric Hall and Carol Hall (2002), who developed stress-coping strategies for teachers related to the following dimensions: interpersonal, emotional, cognitive, physical, task-related, and organisational.

An important factor counteracting professional burnout is social support which manifests itself in emotional support experienced by the individual, support in problem solving, practical and material support, as well as social integration and certainty of connection (J. Szempruch, 2013, pp. 180-183).

The teacher should be provided with support by school workers responsible for the results of teaching and educational work. They may include the principal or their deputies, teacher tutor, a leader of the subject team, a leader of the in-school development programme for teachers, other teachers, a school pedagogue and psychologist, methodological advisors, specialists from psychological and pedagogical clinics, etc. Also, they can come from institutions cooperating with the school.

In burnout prevention, a significant role is also played by educational programmes and courses, training sessions and workshops on how to recognise 
symptoms of the syndrome and effectively counteract them. They are aimed at shaping the time management skill, the ability to set goals and plan their accomplishment, assertiveness, building healthy relations with others, and organising effective rest. The individual concerned should personally take the effort to define their own direction of changes aimed at overcoming professional burnout. This should be preceded by the analysis of the main areas where burnout signs can occur, including:

- overburdening by work - exhaustion, excessive availability, time pressure;

- feeling of lack of control over one's own work - insufficient decision-making and influence opportunities;

- feeling of being underappreciated, insufficient remuneration or lack of satisfaction with work;

- problems with interpersonal relations in the workplace, communication, and obtaining support;

- feeling of injustice and problems with treating workers equally;

- discrepancy between one's own values and the values of the organisation.

Each of these areas involves a separate strategy, implemented in four stages: defining the problem, setting goals, undertaking activities, and tracking progress (M.P Leiter, Ch. Maslach, 2005). Therefore, it is worth applying the above-discussed strategies to overcome professional burnout.

\section{Research Methodology}

\section{Research Questions and Methodology}

In the research conducted, answers were sought to the following questions: What is the level of professional burnout in teachers in the following scopes: emotional exhaustion, depersonalisation, reduced work commitment, narrowing of interpersonal relations and physical tiredness? and What methods are employed by secondary school teachers to counteract professional burnout?

The subject of research required to apply relevant research methodology and techniques as well as an adequate selection of research instruments that would enable adequate measurement of variables significant for the problem under analysis. As the basic method of research, a diagnostic survey was chosen. The following research techniques were used: survey, interview, and analysis of documents. 315 teachers, 6 principals and 6 school pedagogues employed in Lublin and the Starachowice district from the Swiętokrzyskie and Lubelskie provinces participated in the study. The study was conducted over the period 2011-2014. It 
was complemented by individual interviews with 10 randomly selected teachers 5 from each of the provinces. As a result of the study, extensive empirical material characterising the examined variables was collected.

\section{Research Results and Discussion}

Analysis of research results showed that the highest percentage of the surveyed, as many as $45.4 \%$, is characterised by a below-average level of the professional burnout feeling (Chart 1). A very high or high level of burnout was diagnosed in every fifth teacher, and it concerned mostly the appointed and certified teachers with more than 10 years of professional experience (Chart 2).

The highest percentage of the lower secondary school teachers is characterised by a low or very low general level of the professional burnout feeling. The subjects experience emotional exhaustion, depersonalisation, reduced commitment to work and a decrease in the efficacy of their activities, narrowing of interpersonal relations and physical tiredness of marginal intensity, whereas the latter of the listed burnout aspects is most clearly visible in them.

Every third surveyed teacher experiences subjective burnout at an average level. The teachers in this group are characterised by a moderate intensity of exhaustion, lack of commitment to performing their duties, narrowing of inter-

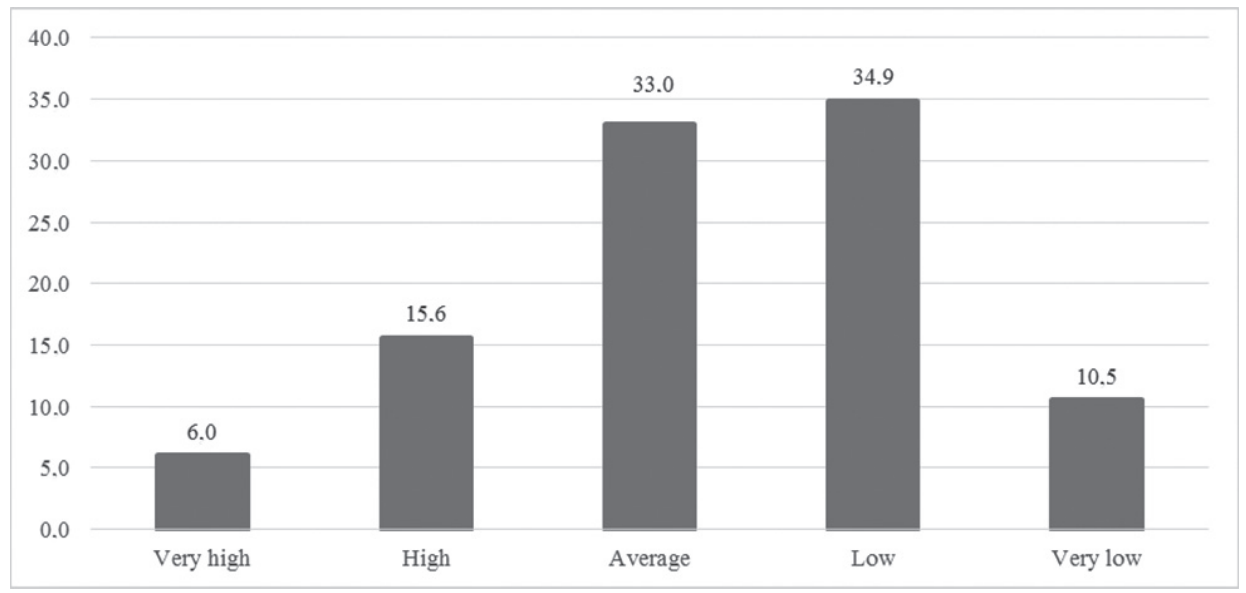

Chart 1. General level of the professional burnout feeling in lower secondary school teachers involved in the survey (\%) 


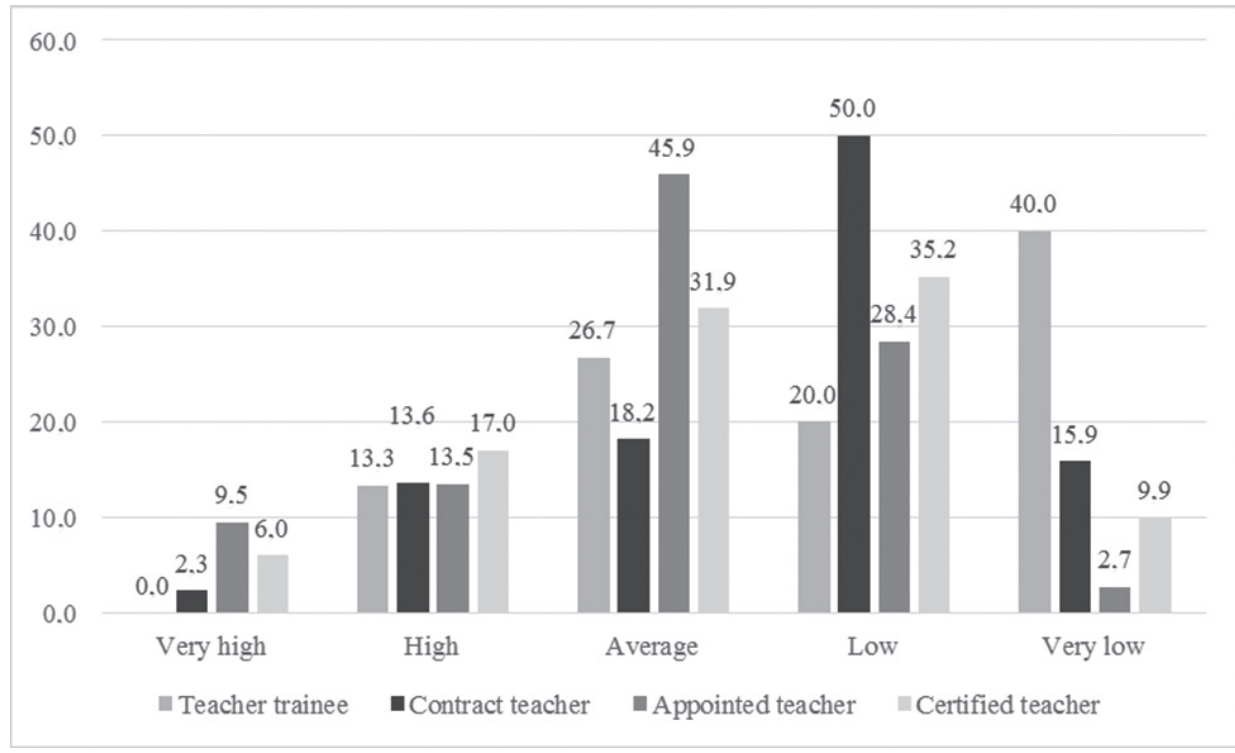

Chart 2. General level of professional burnout feeling vs. level of professional promotion of the surveyed teachers (\%)

personal relationships, and physical tiredness. The latter, along with a tendency to depersonalisation, is slightly higher in them when compared to other groups. A very high or high level of burnout was diagnosed in every fifth teacher. In the case of these teachers, indicators in all the discussed burnout areas are higher than average, with emotional exhaustion, reduced commitment to work and a decrease in the efficacy of activities reaching the highest values. It is highly probable that this group struggles with symptoms that interfere with their professional functioning and shows most numerous signs of full-blown professional burnout.

When analysing the data presenting different areas of professional burnout (Chart 3), one may notice that the largest percentage of the respondents reached a high or very high level of narrowing of interpersonal relations (27.0\%), physical tiredness $(26.1 \%)$, depersonalisation (25.4\%), while a slightly lower percentage emotional exhaustion (21.3\%) and reduced commitment to work and weakened efficacy of activities (18.4\%) (Chart 2). Among the most frequently experienced symptoms of professional burnout, the respondents mentioned "being worn out" after a full day of work (43.2\%), distancing to students (12.1\%), shortening the 


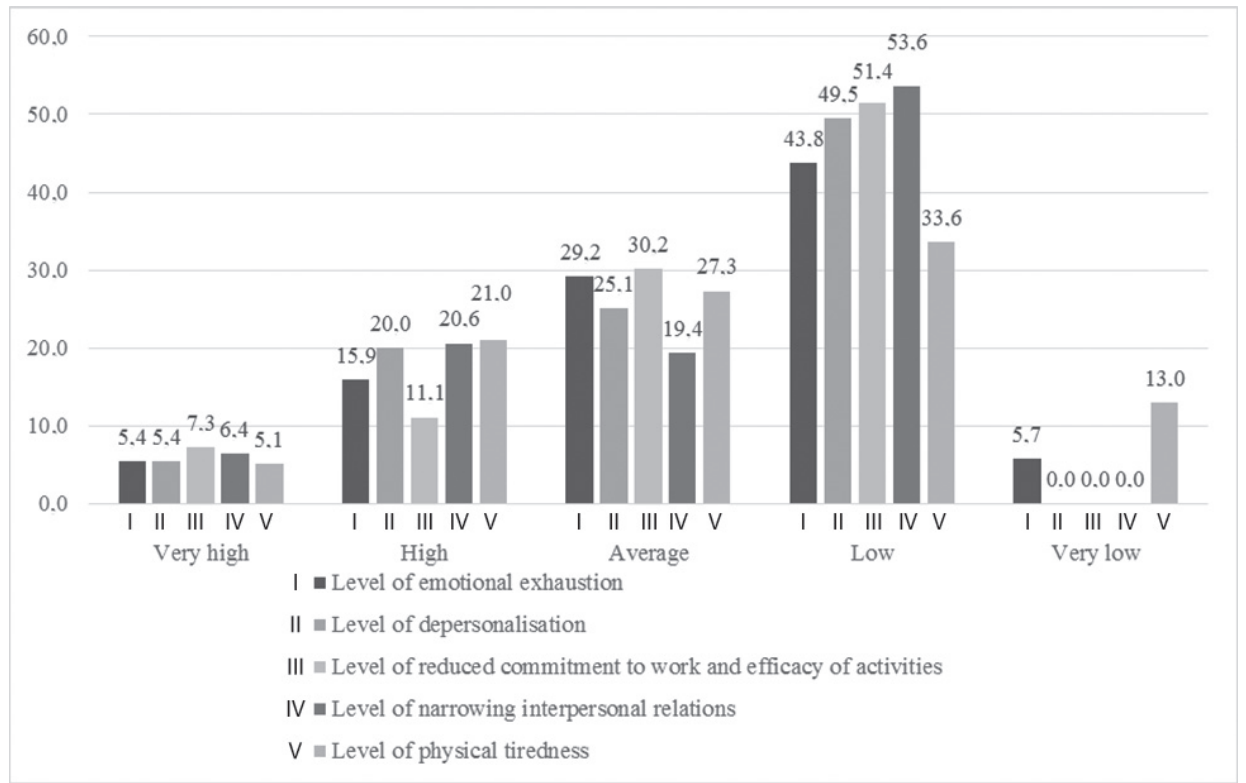

Chart 3. Comparison of the constituent factor levels of the general professional burnout level in surveyed teachers (\%)

time of contact with students outside classes (15.6\%), lack of endeavour to make new acquaintances (22.5\%) and growing impatient when waiting for public holidays (48.6\%).

The surveyed teachers defined the frequency of using various strategies to counteract professional burnout (Table 1). In their opinion, the most effective method in burnout prevention is an active approach to professional tasks and difficulties, a sense of professional efficacy and a positive assessment of events. The teachers highlighted the important role of innovative and creative actions, pursuing extra-professional interests and developing communication skills and a hobby. Among the strategies related to ways of strengthening subjective and environmental resources used by the surveyed teachers, no significant diversification was observed. On average, 3/4 of them often, very often or always undertake professional development activities, set realistic goals, avoid routine and highlight positive aspects to the profession they perform.

Among the strategies focused on the reduction of professional burnout risk factors used by the respondents, the most frequent one was counteracting pathological social phenomena at school such as aggression, violence, addictions. The surveyed 


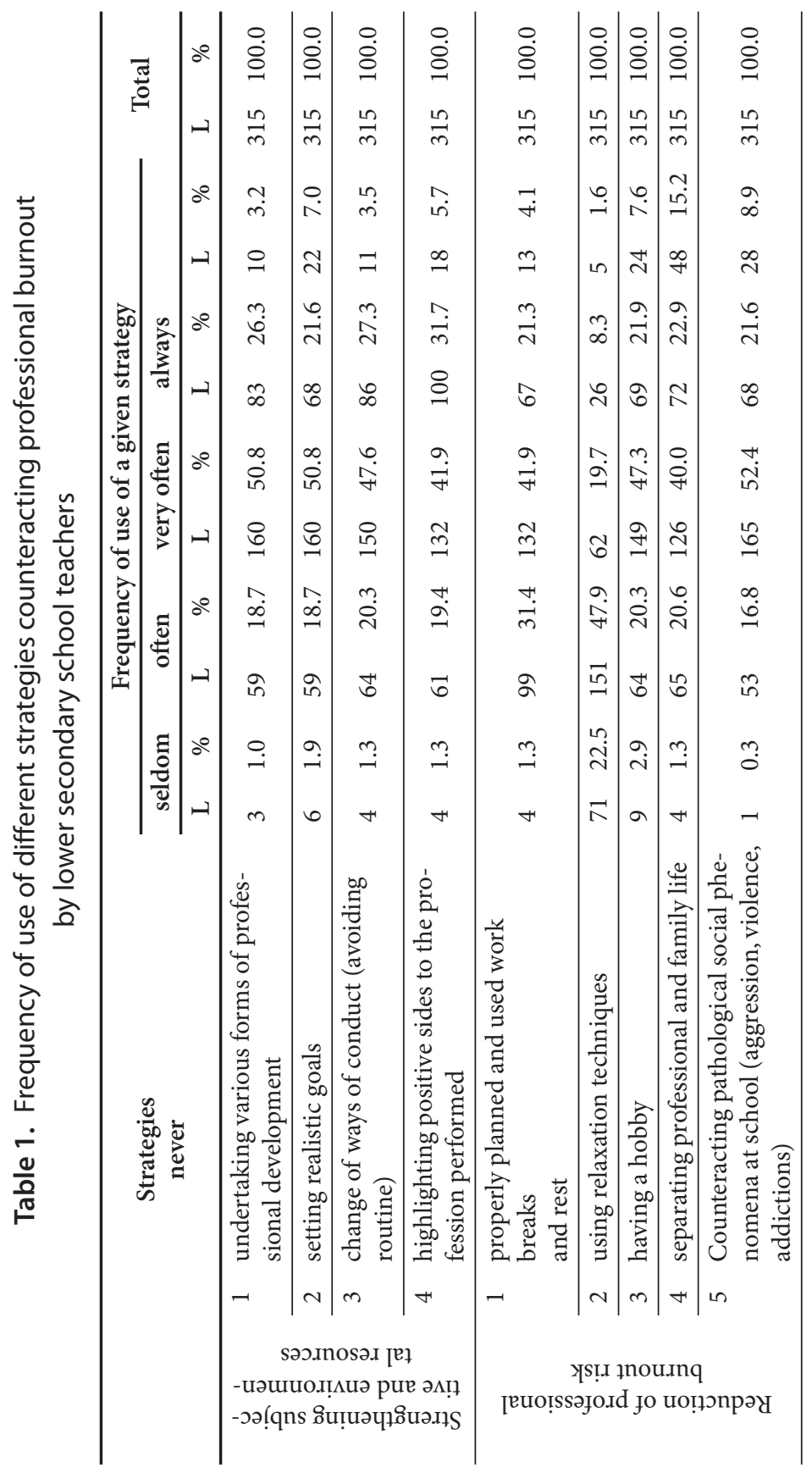


teachers slightly less often separated their professional and family life, developed their interests, properly planned and used work breaks and rest to prevent professional burnout, while relaxation techniques were the least often indicated strategy. It can be concluded, then, that using various methods and techniques effectively protects most of the surveyed teachers against professional burnout.

\section{Conclusion}

The level of the feeling of professional burnout in the surveyed teachers is diversified in terms of professional exhaustion, feeling of depersonalisation, feeling of reduced commitment to work and decrease in the efficacy of activities, narrowing of interpersonal relations and feeling of physical tiredness. The below-average general level of the professional burnout feeling, observed in a numerous group of the respondents, is a favourable phenomenon. However, the number of the teachers in whom a very high or high level of burnout feeling was found, raises concern. Such an assessment was indicated by every fifth surveyed teacher. In the case of these teachers, the indicators in all the discussed burnout areas are above average, whereas the largest intensification of the symptoms indicative of the burnout syndrome in them concerns emotional exhaustion, reduced commitment to work and decrease in efficacy of activities.

An important factor preventing burnout are strategies used by the teachers, including various methods and techniques. The respondents determined the degree to which different processes, features, resources and actions allow them, in their opinion, to protect themselves against professional burnout. In the opinion of the surveyed teachers, the most effective method in burnout prevention is an active approach to professional tasks and difficulties, a sense of professional efficacy and a positive assessment of events. The teachers also believe that creative and innovative actions, development of communication skills, pursuing extra-professional interests, hobbies, and changes in themselves play an important role as effective methods protecting against burnout. The teachers who often use these strategies note a lower level of professional burnout than those who seldom or never use them. In preventing the development of the burnout syndrome, an important role is also played by social support, as frequent use of different sources of help and advice, i.e., one's own family, friends, colleagues and co-workers is associated with a less intense feeling of professional burnout in its various areas. It may be concluded, then, that an elaborated defence system enables the teachers to 
make the workplace less stressful and eliminate the risk of the occurrence of the full-blown burnout syndrome.

Learning about burnout counteracting strategies should be taken into account already at the stage of education of future teachers, and then in various forms of professional development, as efficient use of such strategies is conductive to a high level of professionalism and reduces the risk of professional burnout.

What is also of particular importance is to present to future teachers a realistic picture of the Polish education sector and preparing them as part of the vocational education to cope with unusual educational situations. Good vocational preparation and highly developed professional skills are conducive to constructive problem solving, commitment to the teaching and educational process and a high efficacy of activities.

Measures improving the level of professional functioning of teachers should include improvement of the informing process and consulting with the teacher the environmental changes related to the education reform, as well as any other changes resulting from new regulations and other acts.

\section{References}

Burisch M. (1989), Das Burnout - Syndrom. Teorie der inneren Erschöpfung, Springer Verlag, Berlin, Heidenberg.

Chang M. (2009), An Appraisal Perspective of Teacher Burnout: Examining the Emotional Work of Teachers, "Educational Psychology Review", Vol. 21. No.3

Cherniss C. (1993), Role of Professional Self-Efficacy in the Etiology and Amelioration in Burnout [w:] Professional Burnout: Recent Developments in Theory and Research, red. W.B. Schaufeli, C. Maslach, T. Marek, DC, Taylor \&Francis, Washington.

Edelwich J., Brodsky A. (1980), Burnout. Stages of Disillusionment in the Helpingprofessionals, "Human Science Press", New York.

Friedman I. (2000), Burnout in Teachers: Shattered Dreams of Impeccable Professional Performance, "Psychoterapy in Practice", no. 56 (5).

Hornby G., Hall E., Hall C. (2002), Counselling Pupils in Schools: Skills and Strategies for Teachers, Routledge Falmer, a member of the Taylor\&Francis Group, London.

Maslach C. (1982) Burnout: The Cost of Caring, Englewood Cliffs, NJ, Prentice Hall.

Maslach C., Jackson S. (1986) Maslach Burnout Inventory. Manual (ed. 2.), Palo Alto, CA, Consulting Psychologists Press.

Michael P. Leiter, Christina Maslach (2005), Banishing Burnout: Six Strategies for Improving Your Relationship with Work, Jossey-Bass, San Francisko, CA US.

Monat A., Lazarus R., (1985), Stress and Coping, New York, Columbia University Press. Pines A.M., Aronson E., (1988), Career Burnout: Causes and Cures, New York, Free Press. Szempruch J., (2013), Pedeutologia. Studium teoretyczno-pragmatyczne, (Pedeutology. Theoretical-pragmatic Study). Kraków 2013, Oficyna Wydawnicza "Impuls". 